\title{
Design and synthesis of phenothiazine based push- pull organic sensitizers with benzimidazole as an auxiliary donor for DSC's
}

\begin{abstract}
Three benzimidazole-phenothiazine based organic dyes (SS BP1, SS BP2 and SS BP3) configured with donor - donor $-\pi$ spacer-acceptor (D-D- $\pi-A)$ structures were synthesized with different acceptor units. The optical and electrochemical properties of the dyes was analyzed and compared with suitable references. Based on the obtained results the synthesized dyes are considered to have proper electronic energy levels as promising sensitizers in DSC's. This contribution brings further credit to these molecular designs as efficient sensitizers for DSCs, enroute for a cheap and less toxic substitute to ruthenium based sensitizers and silicon based photovoltaics as potential eco-friendly energy candidates in future.
\end{abstract}

Keywords: benzimidazole, phenothiazine, acceptor unit, DSCs, sensitizer
Volume 2 Issue 3 - 2018

\author{
Sambathkumar S, ${ }^{1,2}$ Priyadharshini S, ${ }^{2}$ Saritha \\ A,' Renganathan $\mathrm{R}^{2}$ \\ 'Department of Chemistry, Theivanai Ammal College for \\ Women (Autonomous), India \\ ${ }^{2}$ School of Chemistry, Bharathidasan University, India
}

Correspondence: Sambathkumar S, Department of Chemistry, Theivanai Ammal College for Women (Autonomous), Villupuram 60540I, India, Tel +9199 9413 4304,

Email sambathkumarraj@gmail.com

Received: December 13,2017| Published: May 212018

\section{Introduction}

Organic materials are suitable for application in light emitting diodes, thin film transistors and photovoltaic devices have received immense attention in recent years. ${ }^{1-3}$ Despite the dominance of metal complexes in electronic devices, because of their favorable electronic structure and superior performances organic molecules continue to have the benefit of research interest due to their versatile functional properties, which in turn, can be fine turned by small structural modifications..$^{4-6}$ Dipolar compounds consisting suitable electronic donor and acceptors have been widely demonstrated as efficient functional materials in electronic devices. ${ }^{7,8}$ Particularly, organic dyes that possess effective intramolecular charge transfer have been found beneficial role as sensitizers in dye sensitized solar cells. ${ }^{9}$ Hence, there is a tremendous progress in metal free sensitizer based DSC's in recent years with efficiencies exceeding 13\% have been reached, using sensitizers which have very high molar extinction coefficients in the visible region..$^{10,11}$

Generally metal free organic dyes possess the general molecular structure of the donor part and the acceptor part bridged by the conjugated linker. Based on the strategy, several arylamine donors have been employed to develop highly efficient organic dyes. ${ }^{12}$ Phenothiazine exhibits a well known electron donating ability, due to its electron rich sulfur and nitrogen heteroatom's. Moreover, the phenothiazine ring is non-planar with butterfly confirmation in the ground state, which can impede the molecular aggregation and the formation of intermolecular excimers which favors phenothiazine based dyes as promising sensitizers for efficient DSC's. ${ }^{13,14}$ On the other hand, organic dyes with D-D-A or D-D- $\pi$-A structure is reported. ${ }^{15-19}$

The D-D- $\pi-A$ structure can achieve the efficient DSC's performance via the modification of the molecular structure compared to organic dyes with simple D- $\pi$-A structure. Further, introduction of additional donor into the dye molecule can increase the electron donating ability of the donor, enhancement in charge separation and electron injection, which lead to the higher conversion efficiencies. ${ }^{20-22}$ Based on these approaches, we design and synthesized three novel phenothiazine based metal free organic dyes with $D-D-\pi-A$ structures consisting of benzimidazole as an additional donor ${ }^{23,24}$ and three different acceptor units. Further, the synthesized dyes were characterized by spectroscopic techniques like, NMR, FT-IR. The optical and electrochemical behavior of the synthesized dyes was systematically analyzed. Additionally, DFT calculations were made in order to highlight the important properties associated with the geometry of the dyes. The corresponding molecular structures of the three dyes (labeled as SS BP1, SS BP2 and SS BP3) are shown in Figure 1.

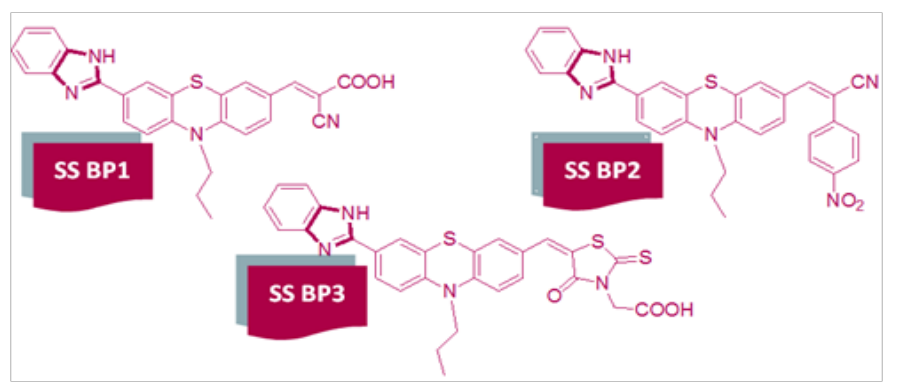

Figure I Structure of the synthesized dyes.

\section{Experimental part}

\section{Synthetic procedures}

General procedure for the synthesis of 10-propyl-10Hphenothiazine (S1); N-alkylation: A dimethyl sulfoxide (DMSO) solution of phenothiazine (2) $(0.5 \mathrm{mmol})$ was allowed to stirred for $30 \mathrm{~min}$. with sodium hydroxide $(\mathrm{NaOH})(0.1 \mathrm{~mol})$ at room temperature. 
To this, propyl bromide $(0.5 \mathrm{mmol})$ was added drop wise and the mixture was stirred at room temperature for 17 hours. The mixture was quenched with water and extracted with ethyl acetate (EtOAc), washed with water, dried in vacuum and the compound was purified by column chromatography (silica gel 60-120 mesh, hexane/EtOAc) $(5: 0.5 \mathrm{v} / \mathrm{v})$ as an eluent to afford the compound (S1) as a white solid.

i. Yield: $85 \%,{ }^{1} \mathrm{H}$ NMR (400MHz, $\left.\mathrm{CDCl}_{3}, \mathrm{ppm}\right): \delta \mathrm{H} 1.0$ (t, 3H, 7.6 $\mathrm{Hz}), 1.8(\mathrm{~m}, 2 \mathrm{H}), 3.8(\mathrm{t}, 2 \mathrm{H}, 7.2 \mathrm{~Hz}), 6.8-6.9(\mathrm{~m}, 4 \mathrm{H}), 7.1(\mathrm{~m}$, $4 \mathrm{H}),{ }^{13} \mathrm{C}$ NMR (400MHz, $\left.\mathrm{CDCl}_{3}, \mathrm{ppm}\right): \delta 145.36,127.45,127.19$, 124.96, 124.35, 115.45, 49.15, 20.19,11.39, IR ( KBr Pellet, $\left.\mathrm{cm}^{-1}\right)$ : 3461, 2967, 2856, 1907, 1675, 1587, 1462, 1127,1026, 831.

General procedure for the synthesis of 10-propyl-10Hphenothiazine-3,7-dicarbaldehyde (S2); vilsmeier - haack formylation: A mixture of $\mathrm{DMF}(0.1 \mathrm{~mol})$ and $\mathrm{POCl}_{3}(4 \mathrm{mmol})$ in $2 \mathrm{ml}$ of 1,2-dichloroethane (DCE) were allowed to cool for $0^{\circ} \mathrm{C}$ and stirred for $30 \mathrm{~min}$. To this, phenothiazine (2) $(0.4 \mathrm{mmol})$ in DCE $(3 \mathrm{ml})$ was added and the mixture was stirred at $100^{\circ} \mathrm{C}$ for 8 hours. The mixture was quenched with ice cooled water and filtered, washed with water, dried in vacuum and the compound was purified by column chromatography (silica gel 60-120 mesh, hexane/EtOAc) $(5: 1 \mathrm{v} / \mathrm{v})$ as an eluent to afford the compound (S2) as a orange solid.

i. Yield: $76 \%,{ }^{1} \mathrm{H}$ NMR $\left(400 \mathrm{MHz}, \mathrm{CDCl}_{3}, \mathrm{ppm}\right): \delta \mathrm{H} 1.0$ (t, 3H, $8.4 \mathrm{~Hz}), 1.8(\mathrm{~m}, 2 \mathrm{H}), 3.8-3.9(\mathrm{t}, 2 \mathrm{H}, 7.6 \mathrm{~Hz}), 6.9(\mathrm{~m}, 2 \mathrm{H}), 7.5-$ $7.6(\mathrm{~m}, 4 \mathrm{H}), 9.8(\mathrm{~s}, 2 \mathrm{H}),{ }^{13} \mathrm{C}$ NMR $\left(400 \mathrm{MHz}, \mathrm{CDCl}_{3}, \mathrm{ppm}\right): \delta$ $189.89,148.90,131.99,130.18,128.41,124.42,115.62,50.19$, 29.99,11.12, IR (KBr Pellet, $\left.\mathrm{cm}^{-1}\right): 3424,2961,2602,1670,1487$, 1353, 1201, 1104, 914

General procedure for the synthesis of 7-(1H-benzoimidazol2-yl)-10-propyl-10H-phenothiazine-3-carbaldehyde

(SP); cyclocondensation: To the stirred solution of 1,2-diaminobenzene $(10 \mathrm{mmol})$ in water $(10 \mathrm{ml})$ about $30 \mathrm{ml}$ of glycerol was added and the temperature of the reaction mixture was slowly increased to $90^{\circ} \mathrm{C}$ followed by the addition of compound S2 $(10 \mathrm{mmol})$ and the reaction mixture was allowed to reflux at $90^{\circ} \mathrm{C}$ for further thours. After confirming the completion of the reaction through thin layer chromatography (TLC) technique, the mixture was quenched with ice and extracted with chloroform $\left(\mathrm{CHCl}_{3}\right)$ filtered, washed with water, dried in vacuum and the compound was purified by column chromatography (silica gel 60-120 mesh, dichloromethane/EtOAc) $(50: 3 \mathrm{v} / \mathrm{v})$ as an eluent to afford the compound (SP) as a dark red solid.

i. Yield: $72 \%$, mp: $162-164^{\circ} \mathrm{C},{ }^{1} \mathrm{H}$ NMR $\left(400 \mathrm{MHz}, \mathrm{CDCl}_{3}, \mathrm{ppm}\right)$ : $\delta \mathrm{H} 1.8(\mathrm{t}, 3 \mathrm{H}, 7.6 \mathrm{~Hz}), 3.8(\mathrm{~m}, 2 \mathrm{H}), 4.0(\mathrm{t}, 2 \mathrm{H}, 26 \mathrm{~Hz}), 6.8-6.9(\mathrm{~m}$, 5H), 7.5-7.6 (m, 5H), $9.8(\mathrm{~s}, 1 \mathrm{H}), 12.6(\mathrm{~s}, 1 \mathrm{H})$, IR (KBr Pellet, $\left.\mathrm{cm}^{-1}\right): 3414,3062,2973,2735,1706,1580,1462,1215,1121,894$, 813.

General procedure for the synthesis of SS BP1, SS BP2 and SS BP3; knoevenagel condensation: $\mathrm{A} \mathrm{CHCl}_{3}$ solution of $\mathrm{P} 2(0.1 \mathrm{mmol}$, $0.2 \mathrm{mmol}$ and $0.5 \mathrm{mmol}$ with respect to SS PI1, SS PI2 and SS PI3) and cyanoacetic acid $(0.2 \mathrm{mmol}$ for SS BP1), 4-nitrophenylacetonitrile $(0.2 \mathrm{mmol}$ for SS BP2) and rhodanine-3-acetic acid $(0.6 \mathrm{mmol}$ for SS BP2) (2mmol) with $0.1 \mathrm{ml}$ of piperidine were allowed to reflux at $70^{\circ} \mathrm{C}$ for 4 hours. The reaction mixture was extracted with $\mathrm{CHCl}_{3}$ and filtered, washed with water, dried in vacuum and the compound was purified by column chromatography (silica gel 60-120 mesh, dichloromethane/ethanol) $(6: 1 \mathrm{v} / \mathrm{v})$ as an eluent to afford the title compounds SS BP1, SS BP2 and SS bP3 as bright yellow solid, brownish red solid and pale orange solid respectively.

3-[7-(1H-benzoimidazol-2-yl)-10-propyl-10H-phenothiazin-3-yl]2-cyano-acrylicacid; compound with methane; (SS BP1): Yield: $40 \%$, mp: $230-232^{\circ} \mathrm{C},{ }^{1} \mathrm{H}$ NMR $\left(400 \mathrm{MHz}, \mathrm{CDCl}_{3}, \mathrm{ppm}\right): \delta \mathrm{H} 1.8(\mathrm{t}$, $3 \mathrm{H}, 5.2 \mathrm{~Hz}), 3.2(\mathrm{~m}, 2 \mathrm{H}), 3.4(\mathrm{t}, 2 \mathrm{H}, 6.0 \mathrm{~Hz}), 6.8(\mathrm{~s}, 1 \mathrm{H}), 7.3-7.4(\mathrm{~m}$, 6H), 7.5-7.6 (m, 10H), 8.0 (s, 1H), IR (KBr Pellet, $\left.\mathrm{cm}^{-1}\right)$ : 3429, 2959, 2862, 2251, 1625, 1461,1356, 1259, 946, 821, 745.

3-[7-(1H-Benzoimidazol-2-yl)-10-propyl-10H-phenothiazin-3yl]-2-(4-nitro-phenyl)-acrylonitrile;(SS BP2): Yield: 53\%, mp: 230-232 ${ }^{\circ} \mathrm{C},{ }^{1} \mathrm{H}$ NMR $\left(400 \mathrm{MHz}, \mathrm{CDCl}_{3}, \mathrm{ppm}\right): \delta \mathrm{H} 1.8$ (t, 3H, $\left.8 \mathrm{~Hz}\right)$, $3.8(\mathrm{~m}, 2 \mathrm{H}), 3.9(\mathrm{t}, 2 \mathrm{H}, 6.4 \mathrm{~Hz}), 6.9(\mathrm{~s}, 1 \mathrm{H}), 7.5(\mathrm{~m}, 3 \mathrm{H}), 7.6(\mathrm{~m}, 2 \mathrm{H})$, 7.6-7.8 (m, 6H), 8.2-8.3 (m, 3H), IR (KBr Pellet, $\left.\mathrm{cm}^{-1}\right)$ : 3428, 3063, $2935,2855,2214,1571,1467,745$.

\{5-[7-(1H-benzoimidazol-2-yl)-10-propyl-10H-phenothiazin3-ylmethylene]-4-oxo-2-thioxo-thiazolidin-3-yl\}-acetic acid; (SS BP3): Yield: $38 \%$, mp: $230-232^{\circ} \mathrm{C},{ }^{1} \mathrm{H}$ NMR $\left(400 \mathrm{MHz}, \mathrm{CDCl}_{3}\right.$, ppm): $\delta \mathrm{H} 1.8$ (t, 3H, 5.2 Hz), $3.2(\mathrm{~m}, 2 \mathrm{H}), 3.4(\mathrm{t}, 2 \mathrm{H}, 6.0 \mathrm{~Hz}), 6.8(\mathrm{~s}$, 1H), 7.3-7.4 (m, 6H), 7.5-7.6(m, 10H), 8.0 (s, 1H), IR (KBr Pellet, $\mathrm{cm}^{-}$ l): 3429, 2937, 2855, 2728, 2527, 1625, 1461, 1386, 1237, 1028, 745.

\section{Results and discussion}

\section{Synthesis and characterization}

The synthetic routes for the novel dyes based on the benzimidazolephenothiazine core are illustrated in Figure 2. The molecular structures of the synthesized dyes (coded as SS BP1, SS BP2 and SS BP3) are shown in Figure 1.

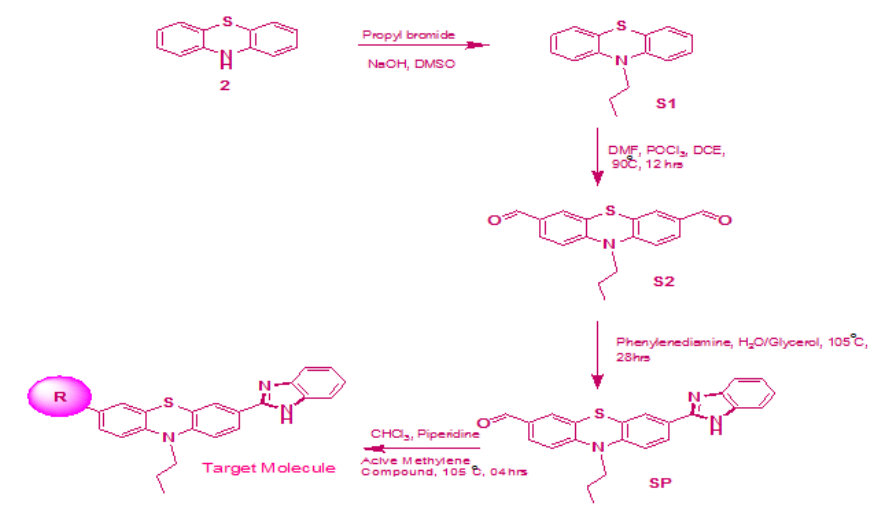

Figure 2 synthetic routes for the novel dyes.

SS BPI (R = Cyanoacetic acid), SS BP2 (R= 4-Nitrophenyl acetonitrile), SS BP3 $(\mathrm{R}=$ Rhodanine-3- acetic acid)

The synthetic pathways for the dyes involved stepwise protocol. First, the compound S1 and S2 prepared according to the reported procedure ${ }^{25,26}$ from compound 2 based on $\mathrm{N}$-alkylation and VilsmeierHaack formylation respectively. Then, 1,2 -diaminobenzene react with S2 in the presence of water and glycerol, which gave the corresponding compound $\mathrm{S} 3$ via cyclocondensation reaction.

Finally, the compound S3 with two fold excess of active methylene compounds (Cyanoacetic acid, Nitrophenyl acetonitrile and Rhodanine acetic acid) afforded the target dyes (SS PI1, SS PI2 and SS PI3) in chloroform with piperidine as catalyst using Knoevenagel condensation. The structure of intermediates and the dye molecules were characterized by ${ }^{1} \mathrm{H}$ and ${ }^{13} \mathrm{C}$ NMR and FT-IR spectroscopic 
techniques (included in appendix III). The difference in the three dyes is majorly related to the acceptor part, which has variation in electron withdrawing nature, where the anchoring of $\mathrm{TiO}_{2}$ occurs.

\section{Optical properties}

To quantify the light absorbing capacity of the dyes, optical spectra of the dyes and their precursors were measured in dichloromethane solution. Absorption spectra of the dyes SS BP1, SS BP2 and SS BP3 are displayed in Figure 3 and the pertinent data compiled in
Table 1. Each of these compounds exhibited two major absorption bands were observed in the range of $250 \mathrm{~nm}-520 \mathrm{~nm}$ with high molar extinction coefficient. The high energy band located at $250 \mathrm{~nm}-$ $310 \mathrm{~nm}$ are attributed to localized aromatic $\pi-\pi^{*}$ transitions of the chromophores, whereas those with lower energy at $400 \mathrm{~nm}-520 \mathrm{~nm}$ are ascribed to intramolecular charge transfer (ICT) from the donor to the acceptor. The intensity of the $\pi-\pi^{*}$ transitions is higher than that of intramolecular charge transfer. The compound with long alkyl chain substituent on the nitrogen atom of phenothiazine displayed a red shift with an increased absorptivity. ${ }^{27}$

Table I Absorption, photoluminescence, electrochemical data and HOMO, LUMO energy levels of the synthesized dyes

\begin{tabular}{|c|c|c|c|c|c|c|}
\hline Dyes & $\lambda_{\mathrm{abs}} / \mathrm{nm}\left(\varepsilon / \mathbf{M}^{-1} \mathrm{~cm}^{-1}\right)^{\mathrm{a}}$ & $\lambda_{\mathrm{em}}(\mathrm{nm})^{\mathrm{b}}$ & $E_{\text {номо }}(\mathbf{V})^{c}$ & $E_{\text {LUMO }}(\mathbf{V})^{d}$ & $E_{g}(e V)^{e}$ & $\mathbf{E}_{\mathrm{ox}} / \mathbf{V}^{\mathrm{f}}$ \\
\hline \multirow{2}{*}{ SS BPI } & $265, * 400$ & 566 & 5.71 & -3.02 & 2.69 & 1.31 \\
\hline & 23,920 & & & & & \\
\hline \multirow{2}{*}{ SS BP2 } & 294,449 & 538 & 5.73 & -3.24 & 2.49 & 1.33 \\
\hline & 29,790 & & & & & \\
\hline \multirow[t]{2}{*}{ SS BP3 } & 307,502 & 546 & 5.53 & -3.17 & 2.36 & 1.13 \\
\hline & 16,860 & & & & & \\
\hline
\end{tabular}

${ }^{a}$ Absorption spectra was measured in Dichloromethane solutions (IXI0-5 M) at rt, *weak absorption band,

'Photoluminescence spectra is measured in N,N-Dimethylformamide solutions (IXI0-6M),

${ }^{c, d} E_{\text {HOMO }}$ and $E_{\text {LUMO }}$ were calculated from the oxidation potential of the dyes and $E_{g}$,

$\mathrm{E}_{\text {Hомо }}=-\left(\mathrm{E}_{\mathrm{Ox} \text { (onset) }}+4.8-\mathrm{E}_{\mathrm{FC}}\right) ; \mathrm{E}_{\text {LUMO }}=\mathrm{E}_{\text {Hомо }}-\mathrm{Eg}$; where $\mathrm{E}_{\mathrm{FC}}$ is potential of internal standard ferrocene,

fOxidation potential of the synthesized dyes ( $\mathrm{ImM}$ ) were obtained from cyclic voltamometry with $0 . \mathrm{IM}_{n} \mathrm{n}$-TBAPF 6 as supporting electrolyte (scanning rate, $300 \mathrm{mV} / \mathrm{s}$; working electrode and counter electrode, $\mathrm{Pt}$ electrode and Pt wire; reference electrode, $\mathrm{Ag} / \mathrm{AgCl}$ ) potentials measured vs $\mathrm{Ag} / \mathrm{AgCl}$ were converted $\mathrm{n}$ to NHE by addition of $0.2 \mathrm{~V}$,

${ }^{\mathrm{e}}$ Eg was estimated from the onset of absorption and photoluminescence spectra of the synthesized dye.

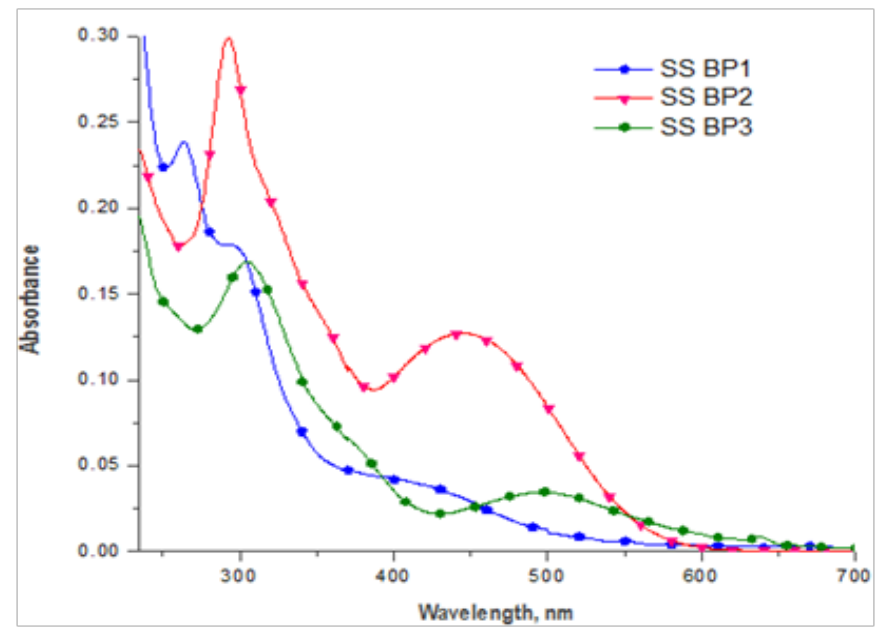

Figure 3 Absorption spectra of the synthesized dyes in $\mathrm{CH}_{2} \mathrm{Cl}_{2}$.

The absorption band of SS BPI2 and SS BP3 with nitrophenyl acetonitrile and rhodanine acetic acid as an acceptor exhibits red shift about $35 \mathrm{~nm}$, compared to that of SS PI1 with cyanoacetic acid anchoring part and this shift is owing to that the nitrophenyl acetonitrile and rhodanine acetic acid units extends the $\pi$ system of the ring via the nitrophenyl ring and 4-oxo-2-thioxothiazolidine ring. ${ }^{28}$ In comparison with SS BP2 and SS BP3, the molar extinction coefficient of SS BP1 is higher, which is an advantageous spectral property for light harvesting ability of DSC's performances. However, the compound SS BP1 exhibits one strong absorption band in shorter wavelength and another one band in the visible region shows weak absorption band, because of the molecular structure of SS BP1 having lesser number of heteroatom as compared with SS BP2 and SS BP3. The two bands observed in the spectra are due to introducing benzimidazole derivative to the framework of phenothiazine core resulting of an improved light harvesting ability. ${ }^{29}$

Particularly compounds SS BP1, SS BP2 and SS BP3 were possesses a wider absorption range (red shift) and higher molar extinction coefficients $\left(38,090 \mathrm{M}^{-1} \mathrm{~cm}^{-1}, 29,790 \mathrm{M}^{-1} \mathrm{~cm}^{-1}\right.$ and 26,860 $\mathrm{M}^{-1} \mathrm{~cm}^{-1}$ ), which should be favorable for photocurrent generation in DSC's because more photons can be harvested. ${ }^{27}$

The absorption spectra of the dyes adsorbed on transparent $\mathrm{TiO}_{2}$ film are shown in Figure 4. The film absorption band displayed a broader band with respect to those in solutions. It appears to be a common phenomenon for such type of most organic dyes, which has been ascribed to the deprotonation of carboxylic acids, as well as the formation of $J$-aggregates ${ }^{30}$ on the $\mathrm{TiO}_{2}$ surface. Notably, all of these dyes exhibit apparent red shifted absorption thresholds of above $650 \mathrm{~nm}$ on $\mathrm{TiO}_{2}$ film compared with those in solution; this match well with the solar spectrum in the visible region. However, the longer alkyl chains could decrease the unfavorable aggregation on the $\mathrm{TiO}_{2}$ 
surface, ${ }^{31}$ which has been suggested accountable for greater DSC's performances.

The emission spectra of the dyes were recorded in dichloromethane solutions (Figure 5) are in similar in nature and the effect peripheral units is not significant. This suggests that this excited state is ICT nature. Based on the intersection of absorption and emission spectra, the zeroth-zeroth transition energies $\left(\mathrm{E}_{0}-\mathrm{E}_{0}\right)$ of the dyes SS BP1, SS BP2 and SS BP3 are estimated to be, $2.81 \mathrm{eV}, 2.39 \mathrm{eV}$ and $2.75 \mathrm{eV}$ respectively. Considering the superior optical properties, we expect to get high short circuit current density $\left(J_{s c}\right)$ for the synthesized dyes.

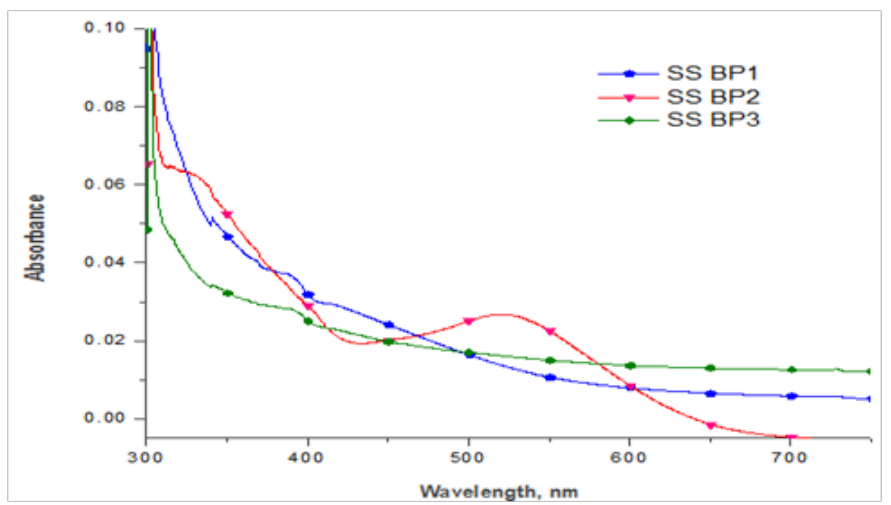

Figure 4 Absorption spectra of $\mathrm{TiO}_{2}$ films sensitized by SS BPI, SS BP2 and SS BP3.

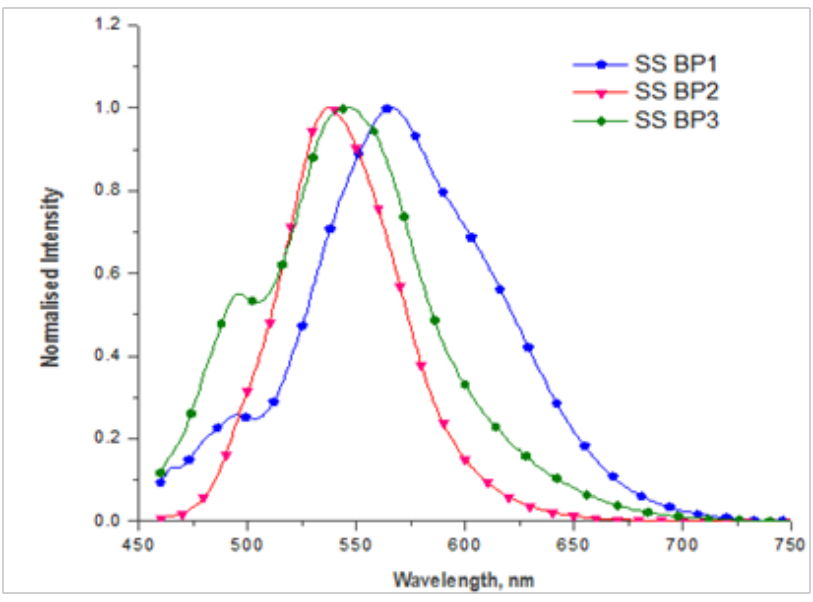

Figure 5 Photoluminescence spectra of the synthesized dyes in $\mathrm{CH}_{2} \mathrm{Cl}_{2}$.

\section{Electrochemical behavior}

Cyclic voltammetry (CV) method was used to investigate the electrochemical properties of the dyes. The relevant electrochemical data are presented in Table 1 and the representative cyclic voltamograms are shown in Figure 6. The oxidation potential $\left(\mathrm{E}_{\mathrm{ox}}\right)$ correspond to HOMOs. as listed in Table 1, the HOMO level of dyes SS BP1, SS BP2 and SS BP3 were $5.71 \mathrm{~V}, 5.73 \mathrm{~V}$ and $5.53 \mathrm{~V}$ $v s$ NHE respectively; these value are more negative than the $\mathrm{I} \mathrm{I}^{-} / \mathrm{I}^{-}$ redox potential value $(0.4 \mathrm{~V} v s \mathrm{NHE})$, indicating that the oxidized dyes could be efficiently regenerated by the electrolyte. The resulting $\mathrm{E}_{0-0}$ values were estimated from the onset of absorption and emission spectra of these dyes. The LUMOs were calculated from the values of $\mathrm{E}_{\mathrm{ox}}$ and the zero-zero band gaps $\left(\mathrm{E}_{0-0}\right)$.
As a result, the LUMO levels of dyes SS BP1, SS BP2 and SS BP3 are $-3.02 \mathrm{~V},-3.24 \mathrm{~V}$ and $-3.17 \mathrm{~V}$ respectively, which are more negative than the conduction band (CB) edge of $\mathrm{TiO}_{2}(-0.5 \mathrm{~V} v s \mathrm{NHE})$, providing the thermodynamic feasibility of electron injection from the excited dye molecules into the $\mathrm{CB}$ of $\mathrm{TiO}_{2}$. According to a report in the literature, the stronger electron donating ability of the donor group results in a higher HOMO energy level..$^{32}$ Generally, a minimal driving force of $0.2 \mathrm{~V}$ is sufficient to ensure fast excited-state injection and regeneration of the oxidized dye. ${ }^{32}$ The schematic energy levels of the dyes based on absorption and electrochemical data are shown in Figure 7. According to Figure 7 these dyes are considered to have proper electronic energy levels as promising sensitizers in DSC's.

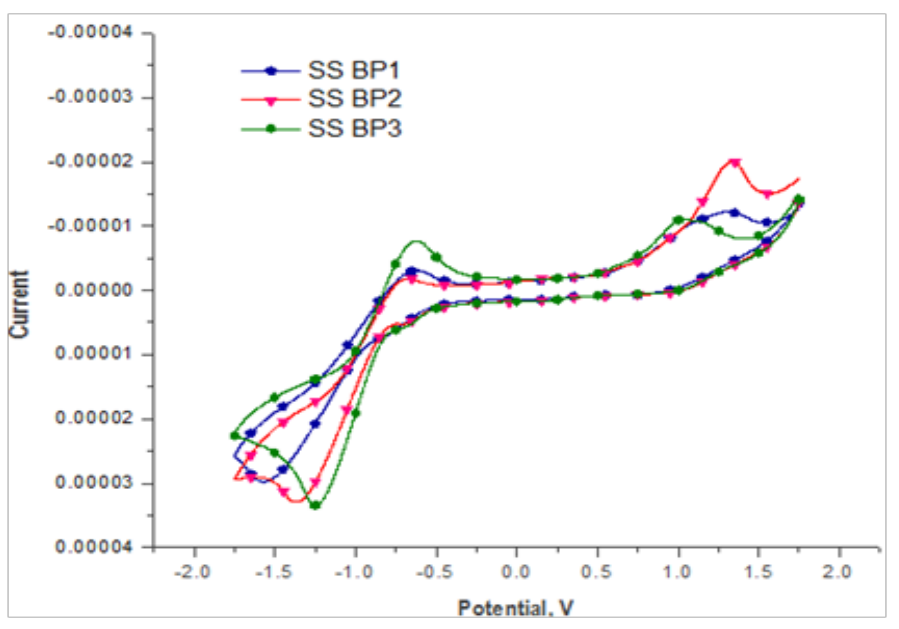

Figure 6 Cyclic voltamograms of the synthesized dyes dissolved in DMF, measured at the scan rate of $300 \mathrm{mV} / \mathrm{sec}$. $\mathrm{Vs} \mathrm{Ag} / \mathrm{AgCl}$.

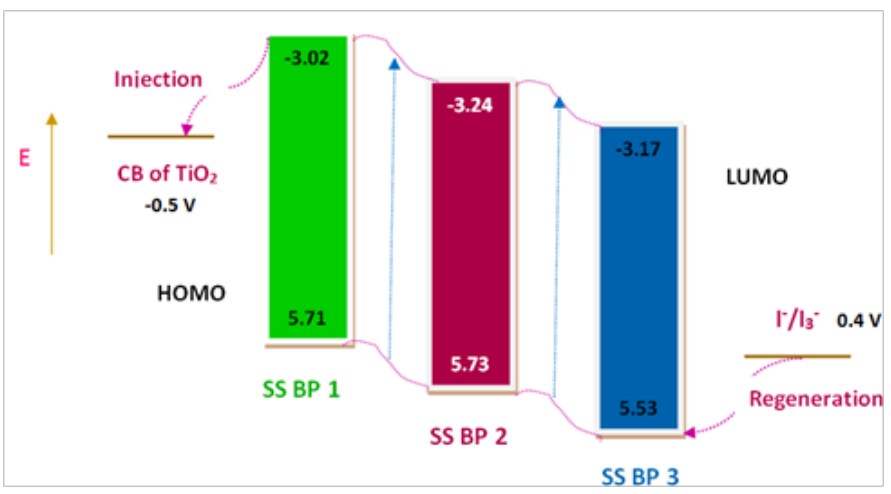

Figure 7 Schematic energy levels of synthesized dyes based on absorption and electrochemical data.

\section{Conclusion}

In conclusion, we have successfully synthesized three novel dyes (SS BP1, SS BP2 and SS BP3) based on an additional donor (benzimidazole derivatives) containing a phenothiazine core bridge donor with three different anchoring units, and established interesting optical and electrochemical properties. The high molar extinction coefficient result in favorable light harvesting efficiencies for DSC's based on the dyes. The additional donor has played significant role in ICT nature. Considering all the ab0ve factors, the best performance of DSC's can be achieved (nearly $5 \%$ as per reported dyes) by using the dyes near future. 


\section{Acknowledgements}

S.S. thanks to University Grants Commission (UGC), Government of India for financial support through the UGB BSR fellowship (Ref. No. F. 4-1/2006 (BSR)/7-22/2007 (BSR) Dt. 26 June, 2012), Department of Science and Technology (DST), Science and Engineering Research Board (SERB), Government of India for International Travel Support (SB/ITS-Y/04782/2014-15, Dt. 30.12.2014) and Department of Science and Technology (DST), Fund for Improvement of S\&T Infrastructure (FIST) for sanctioning DST FIST Program 2017 level '0’ (SR/FST/College - 111/2017; Dt. 16.01.2018).

\section{Conflict of interest}

The authors declare no competing financial interest.

\section{References}

1. Leijtens T, Ding IK, Giovenzana T, et al. Hole transport materials with low glass transition temperatures and high solubility for application in solid-state dye-sensitized solar cells. ACS Nano. 2012;6(2):1455-1462.

2. Justin Thomas KR, Lin JT, Tao YT, et al. Light-Emitting Carbazole Derivatives: Potential Electroluminescent Materials. J Am Chem Soc. 2001;123(38):9404-9411.

3. Li J, Liu D, Li Y, et al. A High Tg Carbazole-Based Hole-Transporting Material for Organic Light-Emitting Devices. Chem Mater. 2005;17(5):1208-1212.

4. Mishra A, Fisher MKR, Bäuerle P. Metal-free organic dyes for dyesensitized solar cells: from structure: property relationships to design rules. Angew Chem Int Ed Engl. 2009;48(14):2474-2499.

5. Mishra A, Fisher MKR, Bäuerle P. Metallfreie organische Farbstoffe für farbstoffsensibilisierte Solarzellen-von Struktur $\square$ Eigenschafts $\square$ Beziehungen zu Designregeln. Angew Chem. 2009;121(14):2510-2536.

6. Regan BO, Grätzel M. A low-cost, high-efficiency solar cell based on dye-sensitized colloidal $\mathrm{TiO}_{2}$ films. Nature. 1991;353:737-740.

7. Lambert C, Schelter J, Fiebig T, et al. Photoinduced Charge Transfer Processes along Triarylamine Redox Cascades. J Am Chem Soc. 2005;127(30):10600-10610.

8. Singh P, Baheti A, Justin Thomas KR. Synthesis and Optical Properties of Acidochromic Amine-Substituted Benzo[a]phenazines. J Org Chem. 2011;76(15):6134-6145.

9. Ying W, Yang J, Wielopolski M, et al. New pyrido[3,4-b]pyrazine-based sensitizers for efficient and stable dye-sensitized solar cells. Chem Sci. 2014;5(1):206-214.

10. Mathew S, Yella A, Gao P, et al. Dye-sensitized solar cells with $13 \%$ efficiency achieved through the molecular engineering of porphyrin sensitizers. Nat Chem. 2014;6(3):242-247.

11. Kakiage K, Aoyama Y, Yano T, et al. Chem Commun. 2007;3741.

12. Sakong C, Kim HJ, Kim SH, et al. Synthesis and applications of new triphenylamine dyes with donor-donor-(bridge)-acceptor structure for organic dye-sensitized solar cells. New J Chem. 2012;36(10):2025-2032.

13. Cheng M, Yang X, Zhang F, et al. Tuning the HOMO and LUMO Energy Levels of Organic Dyes with N-Carboxomethylpyridinium as Acceptor To Optimize the Efficiency of Dye-Sensitized Solar Cells. J Phys Chem C. 2013;117(18):9076-9083.

14. Cheng M, Yang X, Chen C, et al. Effect of the acceptor on the performance of dye-sensitized solar cells. Phys Chem Chem Phys. 2013;15(40):17452-17459.
15. Li G, Zhou YF, Cao XB, et al. Novel TPD-based organic D- $\pi-A$ dyes for dye-sensitized solar cells. Chem Commun. 2009;(16):2201-2203.

16. Ning Z, Zhang Q, Wu W, et al. Starburst Triarylamine Based Dyes for Efficient Dye-Sensitized Solar Cells. J Org Chem. 2008;73(10):3791-3797.

17. Tian H, Yang X, Pan J, et al. A Triphenylamine Dye Model for the Study of Intramolecular Energy Transfer and Charge Transfer in Dye $\square$ Sensitized Solar Cells*. Adv Funct Mater. 2008;18(21):3461-3468.

18. Zhu W, Wu Y, Wang S, et al. Organic D $\square \mathrm{A} \square \pi \square \mathrm{A}$ Solar Cell Sensitizers with Improved Stability and Spectral Response. Adv Funct Mater. 2011;21(4):756-763.

19. Wu Y, Zhang X, Li W, et al. Hexylthiophene $\square$ Featured D-A- $\pi-\mathrm{A}$ Structural Indoline Chromophores for Coadsorbent $\square$ Free and Panchromatic Dye $\square$ Sensitized Solar Cells. Adv Energy Mater. 2012;2(1):149-156.

20. Wang ZS, Koumura N, Cui Y, et al. Hexylthiophene-Functionalized Carbazole Dyes for Efficient Molecular Photovoltaics: Tuning of Solar-Cell Performance by Structural Modification. Chem Mater. 2008;20(12):3993-4003.

21. Dentani T, Kubota Y, Funabiki K, et al. Novel thiophene-conjugated indoline dyes for zinc oxide solar cells. New J Chem. 2009;33(1):93-101.

22. Zhang L, Lu Y, Wang Z, et al. Synthesis of sensitizers containing donor cascade of triarylamine and dimethylaryl - amine moieties for dyesensitized solar cells. Tetrahedron. 2010;66:3318.

23. Zhou L, Jia C, Wan Z, et al. Triphenylamine-based organic dyes containing benzimidazole derivatives for dye-sensitized solar cells. Dyes and Pigments. 2012;95(3):743-750.

24. Wang S, Wang H, Guo J, et al. Influence of the terminal electron donor in D-D- $\pi-\mathrm{A}$ phenothiazine dyes for dye-sensitized solar cells. Dyes and Pigments. 2014;109:96-104.

25. Tian H, Yang X, Chen R, et al. Phenothiazine derivatives for efficient organic dye-sensitized solar cells. Chem Commun. 2007;3741-3743.

26. Wu W, Yang J, Hua J, et al. Efficient and stable dye-sensitized solar cells based on phenothiazine sensitizers with thiophene units. J Mater Chem. 2010;20(9):1772-1779.

27. Yang CJ, Chang YJ, Watanable M, et al. Phenothiazine derivatives as organic sensitizers for highly efficient dye-sensitized solar cells. $J$ Mater Chem. 2012;22(9):4040-4049.

28. Wan Z, Jia C, Duan Y, et al. Effects of different acceptors in phenothiazinetriphenylamine dyes on the optical, electrochemical, and photovoltaic properties. Dyes and Pigments. 2012;94(1):150-155.

29. Zhou L, Jia C, Wan Z, et al. Triphenylamine-based organic dyes containing benzimidazole derivatives for dye-sensitized solar cells. Dyes and Pigments. 2012;95(3):743-750.

30. Sayama K, Tsukagoshi S, Hara K, et al. Photoelectrochemical Properties of J Aggregates of Benzothiazole Merocyanine Dyes on a Nanostructured $\mathrm{TiO}_{2}$ Film. J Phys Chem B. 2002;106(6):1363-1371.

31. Wan Z, Jia C, Wang Y, et al. Significant improvement of phenothiazine organic dye-sensitized solar cell performance using dithiafulvenyl unit as additional donor. Organic Electronics. 2015;27:107-113.

32. Hua Y, Jin B, Wang H, et al. Bulky dendritic triarylamine-based organic dyes for efficient co-adsorbent-free dye-sensitized solar cells. $J$ Power Sources. 2013;237:195-203.

33. Boschloo G, Hagfeldt A. Characteristics of the Iodide/Triiodide Redox Mediator in Dye-Sensitized Solar Cells. Acc Chem Res. 2009;42(11):1819-1826. 